\title{
Giant Lipoma of Hand in a Child: Case Report and Literature Review
}

\author{
Meryam Ramzi ${ }^{1}$, Nada Assara ${ }^{1}$, Zakarya Alami Hassani ${ }^{1 *}$, Zouhir Alami Fellouss ${ }^{2}$, Tariq Madhi ${ }^{2}$
}

${ }^{1}$ Resident Doctor, ${ }^{2}$ Professor of Higher Education, Department of pediatric traumatology and orthopedics, Children's Hospital of Rabat, Ibn Sina UHC/Mohammed V University, Faculty of Medicine and Pharmacy, Rabat, Morocco

DOI: $\underline{10.36347 / \text { sasjs.2022.v08i01.005 }}$

| Received: 06.11.2021 | Accepted: 13.12.2021 | Published: 12.01.2022

*Corresponding author: Zakarya ALAMI HASSANI, MD

Abstract

Case Report

Although lipomas are the most common benign form of soft tissue tumors that are $>5 \mathrm{~cm}$ in diameter. They are extremely rare in the hand localization. They are slowly progressive and usually do not cause numbness or weakness of the hand. They can be deceptively large and extensive leading to misdiagnosis. We present here one such case in which symptomatic swelling over sole of right hand was excised and confirmed as a benign lipoma.

Keywords: Lipoma, Hand.

Copyright $\odot 2022$ The Author(s): This is an open-access article distributed under the terms of the Creative Commons Attribution 4.0 International License (CC BY-NC 4.0) which permits unrestricted use, distribution, and reproduction in any medium for non-commercial use provided the original author and source are credited.

\section{INTRODUCTION}

Lipomas are common tumors that arise from mesenchymal fibrofatty tissue. They are the most common soft tissue tumor.

Although giant lipomas in the hand can extend to vital components such as neurovascular structures, muscles, and tendons, meticulous en bloc resection can provide excellent results without any complications.

\section{CASE REPORT}

We report the case of a child, 10 years old, who presented with a slowly growing tumor in the palm of the left hand. Sensibility and mobility were not affected; he only presented difficulties in grasping and mobilizing the hand due to the large size of the tumor. Anatomically the swelling was located on the area of thenar eminence, was not painful, measured $6 \mathrm{~cm} / 3 \mathrm{~cm}$.

Unltrasound: showed an encapsulated tumor larger than $5 \mathrm{~cm}$, with a fat consistence, images showed the benignity criteria, all in favor of a benign lipoma. A preoparative biopsy was not performed because of high diagnosis reliability provided by the imaging.

The patient underwent surgery (figure 1), the dissection was simple, and a complete excision of the lipoma was performed (figure 2). The functional result has been satisfactory.

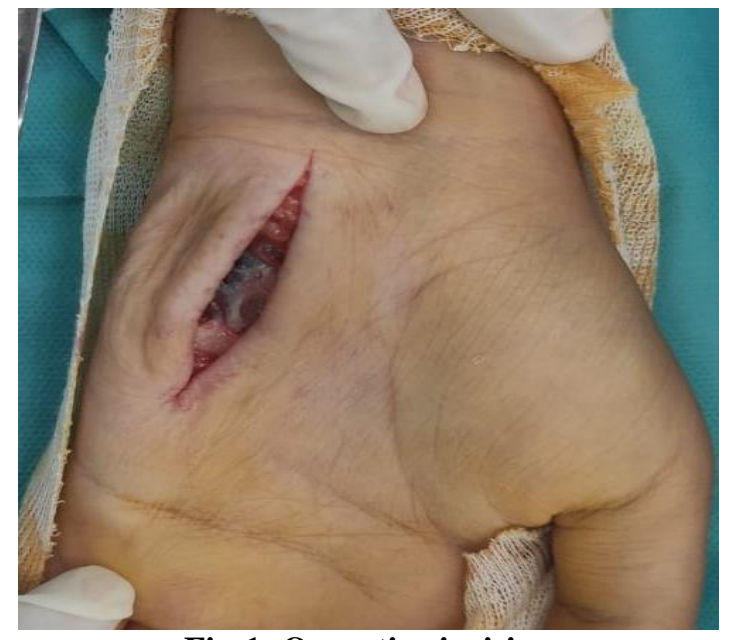

Fig-1: Operative incision

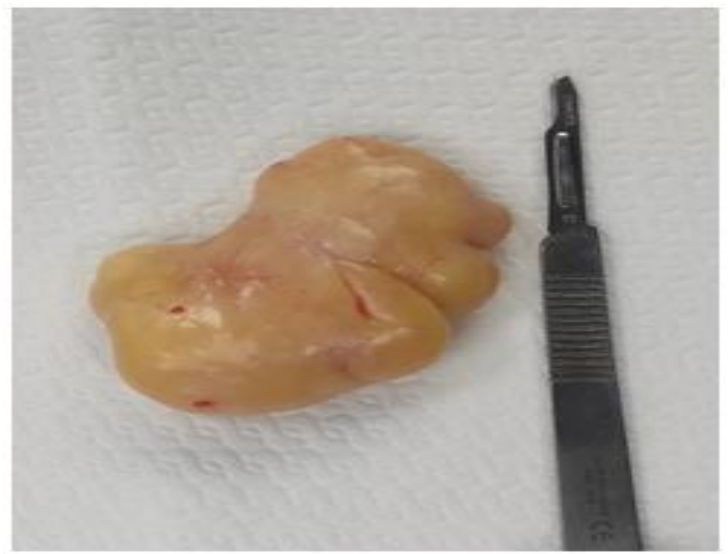

Fig-2: Surgical excision of the lipoma 
The anatomopathological analysis confirmed the diagnosis of benign lipoma.

\section{DISCUSSION}

Giant lipomas are benign tumors larger than 5 $\mathrm{cm}$ in size that are very uncommon in the hand, they represent $5 \%$ of upper limb tumors and about 1 to $3 \%$ of benign tumors of hand, with the extant literature limited to case reports and small case series, especially in child [1].

Giant lipomas of the hand are infrequent tumors of slow growth, generally asymptomatic, although they can cause a compressive symptomatology due to great size. Especially when the extension reaches the carpal tunnel, the hypothenar muscles, or the intertendinous spaces between the left index and little fingers.

Ultrasonography (US), computed tomography (CT), and magnetic resonance imaging (MRI) are used to diagnose lipomas. MRI, in particular, is an important tool because of its high sensitivity rate in finding masses in hands and wrists, at 94\% [2]. MRI results for benign lipomas show clear boundaries and follow the subcutaneous fat signal in all sequences, with very thin septations.

Tissue mass larger than $5 \mathrm{~cm}$ must be
$\begin{aligned} & \text { considered } \\ & \text { anatomopathological study of the specimen is crucial. }\end{aligned}$

The majority of the cases reported in the literature have demonstrated that surgical excision of lipomas has good results for functional recovery.

The most frequent complications are, postoperative infection, injuries of the neurovascular structures, complex regional pain syndrome, and local recurrences, they are rare, usually caused by incomplete tumor excision.

\section{CONCULSION}

Giant lipomas of the hand are benign tumors composed of adipose tissue that can appear anywhere on the body. Rarely in the hands does wich appear as a slow-growing, painless, and soft lump?

Ultrasonography (US), computed tomography (CT), and magnetic resonance imaging (MRI) are used for diagnosis.

Exision is simple and the results are excellent when there is no extention to vital components such as neurovascular structures, muscles and tendon.

\section{Competing interests}

The authors declare no competing interest.

\section{RÉFÉRENCES}

1. Lisenda, L., van Deventer, S., Pikor, T., \& Lukhele, M. (2013). Case report: Giant lipoma of the hand. SA Orthopaedic Journal, 12(3), 46-48.

2. Papakostas, T., Tsovilis, A. E., \& Pakos, E. E. (2016). Intramuscular lipoma of the thenar: a rare case. Archives of Bone and Joint Surgery, 4(1), 80. 